Research Paper

\title{
Differences in C-type lectin receptors and their adaptor molecules in the peritoneal fluid of patients with endometriosis and gynecologic cancers
}

\author{
Seung Geun Yeo ${ }^{1}$, Yong Sung Won², Sang Hoon Kim¹, Dong Choon Park ${ }^{3 凶}$ \\ 1. Medical Science Research Institute, Kyung Hee University Medical Center, Kyung Hee University, Seoul 130-872, Republic of Korea \\ 2. Department of General Surgery, St. Vincent's Hospital, The Catholic University of Korea, Suwon, Korea \\ 3. Department of Obstetrics and Gynecology, St. Vincent's Hospital, The Catholic University of Korea, , Suwon, Korea
}

$\square$ Corresponding author: Dong Choon Park, M.D., PhD. Department of Obstetrics and Gynecology, St. Vincent's Hospital, College of Medicine, The Catholic University of Korea, 93, Jungbu-daero, Paldal-gu, Suwon, Gyeonggi-do, 16247, Republic of Korea. Phone: 82-31-249-8221, Fax: 82-31-254-7481, E-mail:park.dongchoon@gmail.com

(c) Ivyspring International Publisher. This is an open access article distributed under the terms of the Creative Commons Attribution (CC BY-NC) license (https://creativecommons.org/licenses/by-nc/4.0/). See http://ivyspring.com/terms for full terms and conditions.

Received: 2017.10.17; Accepted: 2018.01.05; Published: 2018.02.12

\begin{abstract}
Endometriosis, although not malignant, has clinically demonstrated properties of invasiveness and metastasis. The pathogenesis of endometriosis, however, has not yet been elucidated. The immunological differences between endometriosis and malignant gynecologic tumors were analyzed by assessing C-type lectin receptors, which are associated with innate immunity, and immunoglobulin secretion, which is associated with B cell adaptive immunity, in the peritoneal fluid of these patients. Peritoneal fluid samples were obtained from 42 patients with benign masses (control group), 38 with endometriosis, and 43 with gynecologic (ovarian, uterine, and cervical) cancers. The levels of expression in these samples of mRNAs encoding the C-type lectin receptors Dectin-1, MR1, MR2, DC-SIGN, Syk, Card 9, Bcl 10, Malt 1, src, Dec 205, Galectin, Tim 3, Trem 1, and DAP 12, were measured by real-time reverse transcription polymerase chain reaction, and the concentrations of $\operatorname{lgG}$, IgA and IgM were measured by enzyme-linked immunosorbent assays (ELISA). Findings in the three groups were compared. The level of galectin mRNA was significantly lower, and the levels of MR2 and DAP 12 mRNAs significantly higher, in the endometriosis than in the control group $(p<0.05$ each). Compared with the gynecologic cancer group, the level of $\mathrm{Bcl} 10$ mRNA was significantly lower, and the levels of MR1, MR2, Syk, Card 9, Malt 1, Dec 205, Tim 3, and DAP 12 mRNAs significantly higher, in the endometriosis group ( $<<0.05$ each). The levels of MR2 and DAP 12 mRNAs were significantly higher in the endometriosis than in the control group $(p<0.05$ each), whereas the level of galectin mRNA was similar in the endometriosis and gynecologic cancer groups. IgA and IgG concentrations in peritoneal fluid were significantly lower in the gynecologic cancer than in the control group ( $p<0.05$ each). However, concentrations of all three immunoglobulins in the endometriosis group did not differ from those in the other two groups $(p>0.05)$. C-type lectin receptors and immunoglobulins act cooperatively and are closely associated in the pathogenesis of endometriosis. The decreased expression of galectin mRNA in the peritoneal fluid of the endometriosis group suggests that endometriosis and gynecologic cancers have similar immunologic characteristics.
\end{abstract}

Key words: Endometriosis, Gynecologic cancer, C-type lectin receptors, Immunoglobulin

\section{Introduction}

Endometriosis is a disease associated with chronic pelvic inflammation. In addition to being a major cause of pelvic pain, endometriosis may be accompanied by dysmenorrhea, dyspareunia, infertility and menstrual irregularities. Although not a malignant disease, endometriosis invades surround- 
ing organs $[1,2]$.

Despite the importance of endometriosis, its exact pathogenesis has not been determined. Although immune cells, such as macrophages, dendritic, cytokines, B cells, and natural killer cells, are present in the abdominal cavity of patients with endometriosis, these cells cannot remove ectopic endometrial cells. Understanding the mechanisms underlying this lack of activity, the function of immune system cells, and the interactions between immune cells are important in determining the pathophysiology of endometriosis[3,4]

The progression of endometriosis leads to the reaction of immune cells and their secretion of effector molecules into the abdominal cavity. Few studies to date, however, have analyzed the roles of C-type lectin receptors and their adaptor molecules in endometriosis, including the roles of components of the innate immune system, such as pattern recognition receptors (PRRs), Toll-like receptors (TLRs), and cytoplasmic nucleotide-binding oligomerization domains (NOD)-like receptors (NLRs)[5,6].

This study therefore investigated components of the innate immune response, including C-type lectin receptors and their adaptor molecules; components of the acquired immune response, such as immunoglobulins (Igs); and their relationship to each other in the peritoneal fluid of patients with endometriosis. The relationship between these factors and the clinical characteristics of these patients was also analyzed. These findings were compared with results obtained from groups of patients with benign and malignant diseases.

\section{Materials and Methods}

\section{Subjects}

Intraperitoneal fluid samples were collected during laparoscopy or laparotomy from 123 patients with gynecologic disease. Peritoneal fluid was collected aseptically from the Douglas pouch, taking care to avoid bleeding. Patients with a hormone producing condition, including pregnancy; those without peritoneal fluid and those with peritoneal fluid contaminated with blood; those with peritonitis; and those with any other immunologic disease were excluded from the study. Peritoneal fluid samples were centrifuged at $1800 \times \mathrm{g}$ for $10 \mathrm{~min}$; the supernatants were stored at $-80^{\circ} \mathrm{C}$ in $1.5 \mathrm{ml}$ aliquots; and the cell pellets were stored at $-80^{\circ} \mathrm{C}$ in $1.5 \mathrm{ml}$ aliquots after adding RNase inhibitor. The study protocol was approved by the institutional review boards (IRBs) of St. Vincent's Hospital, The Catholic University of Korea, with all patients providing written informed consent (VC16TISI0148).

\section{RNA extraction and real-time PCR}

Total RNA was purified from peritoneal fluid using TRIzol solution, according to the manufacturer's protocol (Invitrogen, Carlsbad, CA, USA). First-strand cDNA was synthesized from $1 \mu \mathrm{g}$ aliquots of total RNA using a reverse transcription system with random hexamers (Promega, Madison, WI, USA) according to the manufacturer's protocol. Real-time PCR was performed on a StepOnePlus real-time PCR system with Power SYBR Green PCR Master Mix (Applied Biosystems, Foster City, CA, USA). Each $20-\mu 1$ PCR reaction mixture included $1 \mu 1$ of cDNA, $10 \mu \mathrm{l}$ of Power SYBR Green PCR Master Mix, $2 \mu 1$ of primers (Table 1), and $7 \mu 1$ of PCR-grade water. The amplification protocol consisted of an initial denaturation at $95^{\circ} \mathrm{C}$ for $10 \mathrm{~min}$, followed by 40 cycles of denaturation at $95^{\circ} \mathrm{C}$ for $15 \mathrm{~s}$ and annealing and extension at $60^{\circ} \mathrm{Cfor} 1 \mathrm{~min}$. The crossing points of the target genes with $\beta$-actin were calculated using the formula 2 -(target gene- $\beta$-actin), and relative amounts were quantified.

Table 1. Primers for real-time RT-PCR

\begin{tabular}{|c|c|c|c|}
\hline Name & Sequences & $\begin{array}{l}\text { Product } \\
\text { size (bp) }\end{array}$ & $\begin{array}{l}\text { Accession } \\
\text { number }\end{array}$ \\
\hline \multirow[t]{2}{*}{ Dectin-1 } & 5'-GACTGAGGTACCATGGCTCTG-3' & 93 & NM022570 \\
\hline & 5'-GGAGATGGGTTTTCTTGGGT-3' & & \\
\hline \multirow[t]{2}{*}{ MR1 } & 5'-GGGTGCTGTTCTCCTACTGG-3' & 140 & NM002438 \\
\hline & 5'-CCCATCGGAATTTCTGTGAT-3' & & \\
\hline \multirow[t]{2}{*}{ MR2 } & 5'-GCTGCGTCCTGCTCCTC-3' & 104 & NM006039 \\
\hline & 5'-CAGTCCATGGCTGAAGATGA-3' & & \\
\hline \multirow[t]{2}{*}{ DC-SIGN } & 5'-AAGTAACCGCTTCACCTGGA-3' & 123 & NM021155 \\
\hline & 5'-TTGTTGGGCTCTCCTCTGTT-3' & & \\
\hline \multirow[t]{2}{*}{ Syk } & 5'-GAGAGCGAGGAGGAGCG-3' & 148 & NM00317 \\
\hline & 5'-AAAGAAGGGCAGGTGGTTG-3' & & \\
\hline \multirow[t]{2}{*}{ Card-9 } & 5'-TCCAAGATGTACAAGGACCG-3' & 105 & NM052813 \\
\hline & 5'-CTGTGCGTGCAGCTCCT-3' & & \\
\hline \multirow[t]{2}{*}{ Bcl-10 } & 5'-TCCCTCACCGAGGAGGAC-3' & 112 & NM00392 \\
\hline & 5'-TTGCACGTAGATGATCAAAATGT-3' & & \\
\hline \multirow[t]{2}{*}{ Malt-1 } & 5'-TTTCCTGCAGGCTATGGAAC-3' & 96 & NM00678 \\
\hline & 5'-GCCAAGACTGCCTTTGACTC-3' & & \\
\hline \multirow[t]{2}{*}{ Src } & 5'-CTGTCCTTCAAGAAAGGCGA-3' & 110 & NM00541 \\
\hline & 5'-TAGTTGCTGGGGATGTAGCC-3' & & \\
\hline \multirow[t]{2}{*}{ Dec-205 } & 5'-TGGCTTCATGGGTCATGTTA-3' & 130 & NM00234 \\
\hline & 5'-CCAGCCAAAAACTTCTCATTT-3' & & \\
\hline \multirow[t]{2}{*}{ Galectin-1 } & 5'-CAAACCTGGAGAGTGCCTTC-3' & 90 & NM00230 \\
\hline & 5'-AGGTTGTTGCTGTCTTTGCC-3' & & \\
\hline \multirow[t]{2}{*}{ Tim-3 } & 5'-CTTCGGCGCTTTAATTTTCA-3' & 124 & NM03278 \\
\hline & 5'-GCGAATTCCCTCTGCTACTG-3' & & \\
\hline \multirow[t]{2}{*}{ Trem-1 } & 5'-CCGATGTCTCCACTCCTGAC-3' & 108 & NM018643 \\
\hline & 5'-TACTCAGGAATCCACCAGCC-3' & & \\
\hline \multirow[t]{2}{*}{ DAP-12 } & 5'-GAGACCGAGTCGCCTTATCA-3' & 101 & NM003332 \\
\hline & 5'-GTCATGATTCGGGCTCATTT-3' & & \\
\hline \multirow[t]{2}{*}{$\beta$-actin } & 5'-GCGAGAAGATGACCCAGATC-3' & 77 & NM001101 \\
\hline & 5'-GGATAGCACAGCCTGGATAG-3' & & \\
\hline
\end{tabular}

Abbreviations: RT-PCR, reverse transcriptase-polymerase chain reaction; Dectin-1, dendrite cell-associated C-type lectin-1; MR1, mannose receptor 1; MR2, mannose receptor 2; DC-SIGN, dendritic cell-specific ICAM3-grabbing non-integrin; Syk, spleen tyrosine kinase; Card-9, caspase-recruitment domain family, member 9; Bcl-10, B cell lymphoma 10; Malt-1, mucosa-associated lymphoid tissue lymphoma translocation gene 1; Src, steroid receptor co-activator; Dec-205, Dendritic and epithelial cell-205; Tim-3, T cell immunoglobulin mucin-3; Trem-1, triggering receptor expressed on myeloid cells-1; DAP-12, DNAX-activating protein of 12 $\mathrm{kDa}$. 


\section{Enzyme-linked immunosorbent assay}

All samples of ascites fluid were stored at $-80^{\circ} \mathrm{C}$, and their IgG, IgA, and IgM concentrations were measured by enzyme-linked immunosorbent assay (ELISA, Bethyl, Montgomery, TX, USA). Briefly, 100 $\mu 1$ of diluted 1:100 goat anti-human IgA, IgG, IgM in coating buffer (0.05 M Carbonate-Bicarbonate, $\mathrm{pH}$ 9.6) were placed in each well of a 96-well plate, and the plates were incubated at room temperature for $1 \mathrm{~h}$. The wells were washed five times, blocking antibody was added, followed by the addition of $200 \mu \mathrm{l}$ of sample, and the plates were incubated at room temperature for $30 \mathrm{~min}$. The wells were washed five times, $100 \mu \mathrm{l}$ of diluted goat anti-human IgA, IgG, IgM-horseradish peroxidase (HRP) were added to each well, and the plates were incubated at room temperature for $1 \mathrm{~h}$. The plates were washed five times, $100 \mu \mathrm{l}$ of tetramethylbenzidine (TMB) substrate solution were added, and the plates were incubated for $15 \mathrm{~min}$ in the dark at room temperature, followed by the addition of $100 \mu$ l of stop solution. The plates were read at an optical density of $450 \mathrm{~nm}$ on a microtiter plate reader. Antibody titers were calculated by comparing the optimal density of sample wells to those of standard serum. All ELISA tests were performed in duplicate and their means were calculated.

\section{Statistical analysis.}

The Kolmogorov-Smirnov test was used to assess normality and Levene's test was used to assess the equality of variances between groups. Between group-differences in expression were determined using independent t-tests, with correlations assessed using the Pearson correlation test.

All statistical analyses were performed using SPSS version 13, with a p-value less than 0.05 considered statistically significant.

\section{Results}

\section{Characteristics of Patients in the Control and Experimental Groups}

This study enrolled 123patients, comprising 42controls, 38with endometriosis, and 43with gynecologic cancers. Mean overall patient age was $44 \pm 3.3$ years in the control group, $31 \pm 4.4$ years in the endometriosis group and $56 \pm 4.7$ years in the gynecologic cancer group.

\section{Expression of C-type lectin receptormRNAs in peritoneal fluid (Figure 1)}

Expression of mRNAs encoding all C-type lectin receptors assayed was observed in the effusion fluid samples of patients in all three groups. The levels of
mRNAs encoding all C-type lectin receptors, except Bcl-10, Src, and DAP-12, were significantly lower in the gynecologic cancer than in the control and endometriosis groups. For example, the levels of MR1, Syk, Card 9, Malt 1, Dec 205, Galectin, and Tim 3 mRNAs were significantly lower, while the level of $\mathrm{Bcl} 10$ mRNA was significantly higher, in the gynecologic cancer than in the other two groups ( $p$ $<0.05$ each). In addition, the level of DAP 12 was significantly higher in the gynecologic cancer than in the control group $(\mathrm{p}<0.05)$.

The levels of MR1, Syk, Card-9, Malt-1, Dec-205, Tim-3, and DAP-12 mRNAs were significantly higher, while the level of Bcl-10 mRNA was significantly lower, in the endometriosis than in the gynecologic cancer group ( $p<0.05$ each). In addition, the level of MR2 mRNA was significantly higher in the endometriosis than in the control and gynecologic cancer groups $(\mathrm{p}<0.05)$.

\section{Concentrations of Igs in effusion fluid (Figure 2)}

Levels of secreted IgG, IgA, and IgM were significantly lower in the gynecologic cancer than in the control and endometriosis groups ( $p<0.05$ each). However there were no significant differences between the endometriosis and control groups $(\mathrm{p}>0.05)$.

\section{Correlations of C-type lectin receptor expres- sion and Ig concentrations (Table 2, 3, 4)}

In the control group, DC-SIGN and DAP 12 mRNA levels correlated with IgG concentration and Src mRNA level correlated with IgM concentration. In the endometriosis group, Bcl 10 mRNA level correlated with IgA concentration, and Syk and Trem 1 mRNA levels correlated with IgM concentration. In the gynecologic cancer group, DC-SIGN mRNA level correlated significantly with IgG concentration, and Syk mRNA level correlated significantly with IgM concentration $(p<0.05$ each).

\section{Discussion}

Endometriosis is a leading cause of pelvic pain, dysmenorrhea, dyspareunia, and infertility, but its pathophysiology is not yet known. In particular, the immunological aspects of its pathophysiology are thought to be related to the innate immune response, but the exact mechanisms remain unknown $[2,3]$.

Although symptom severity does not correlate with the progression of endometriosis, the latter involves the secretion of various molecules, including cytokines, chemokines, and Igs. Autophagy, ER stress, and immune cells are also involved in the progression of endometriosis. All of these factors are associated with symptoms of this condition. 


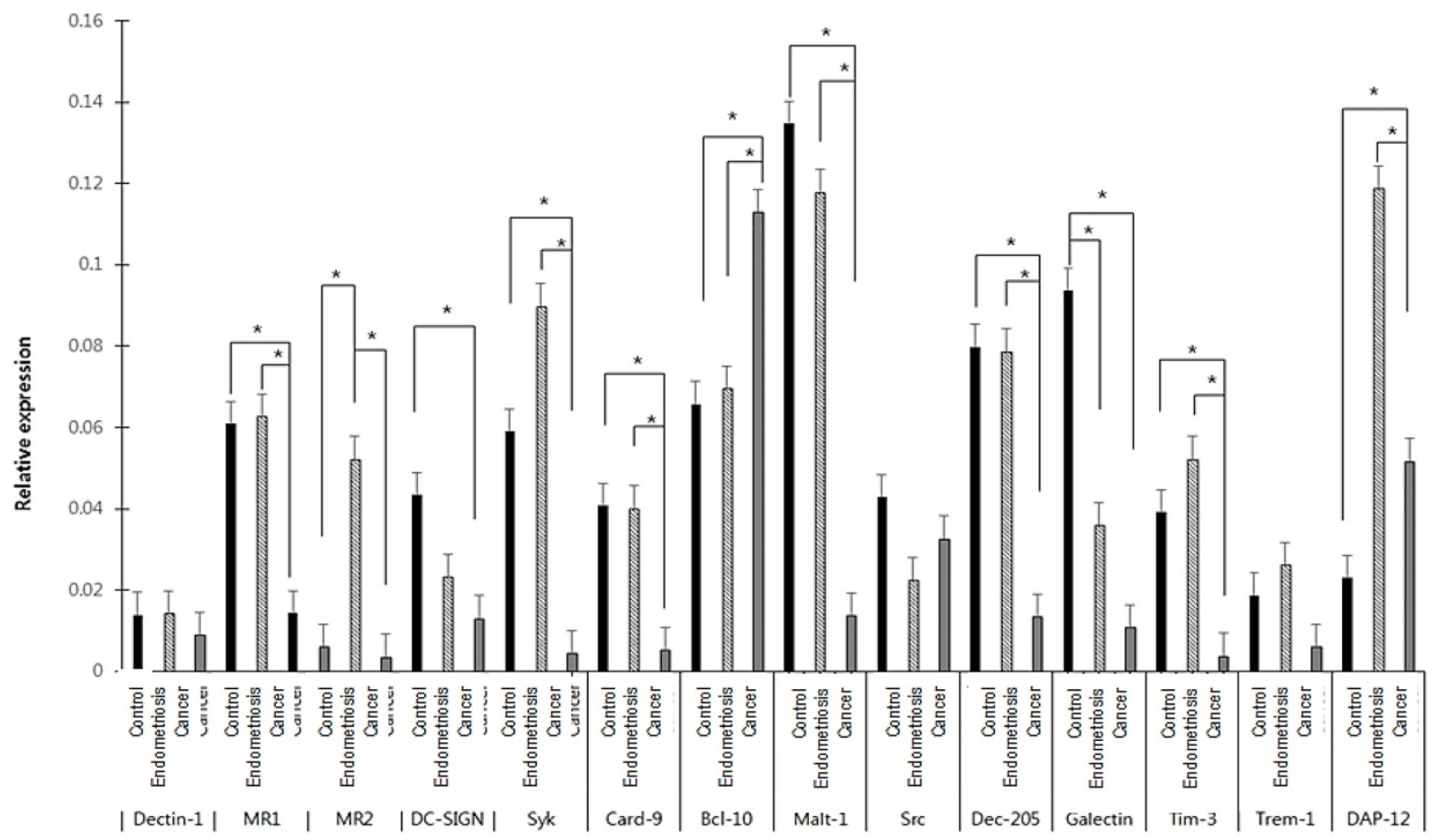

Figure 1. Expression of mRNAs encoding CLRs in the normal, endometriosis and gynecologic cancer groups. *p $<0.05$

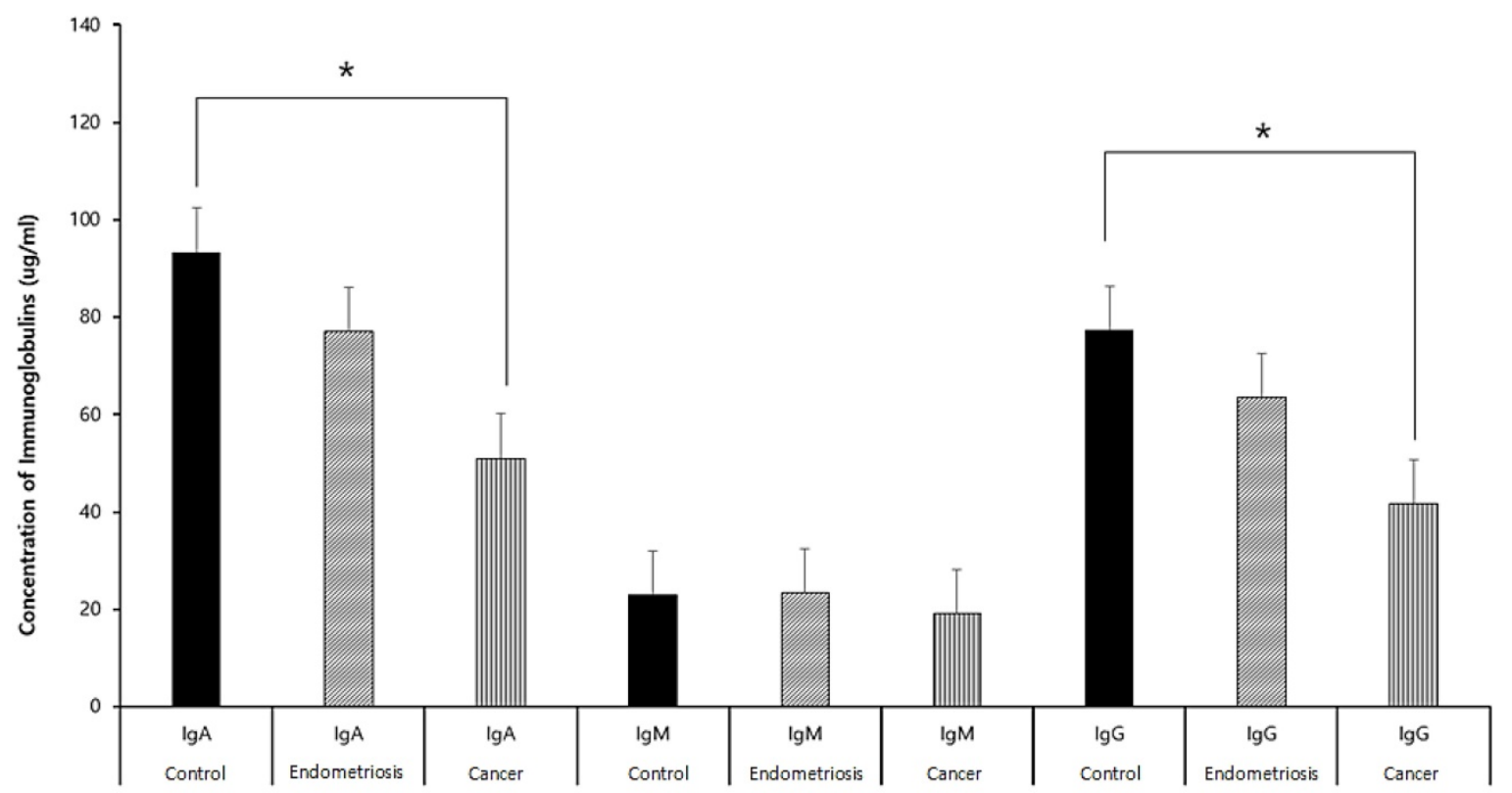

Figure 2. Concentrations of $\lg \mathrm{A}$, $\lg \mathrm{M}$, and $\lg \mathrm{G}$ in the peritoneal fluids of patients in the control, endometriosis, and gynecologic cancer groups.* ${ }^{*}<0.05$

Initially, gynecologic cancers are limited to the primary lesion but gradually progress to invasion and/or metastasis to other organs. Pathways are primarily lymphatic, hematogenous, and direct metastasis, which produce malignant ascites fluid in the abdominal cavity. Although endometriosis is a benign disease, its infiltration of peripheral organs and invasion of distant organs resembles metastasis of malignant disease[7-9].

PRRs are important constituents of the innate immune system that recognize and bind to pathogen-associated molecular patterns (PAMPs) on pathogens. Types of PRRs include TLRs, NLRs, retinoic acid-inducible genes (RIG-I) and C-type lectin receptors. Excessive upregulation of PRRs may accelerate cell proliferation in endometriosis and may 
be associated with carcinogenesis. We previously reported that mRNAs encoding TLRs-1, -2, -4, -5, -6, and -9 and NODs- 1 and -2 were expressed in both endometriosis and non-endometriosis benign diseases, with the levels of expression of TLR-2 and -9 and NOD-1 and -2 mRNAs being significantly higher in patients with than without endometriosis. These findings suggest that innate immune activity is increased in the abdominal cavity of patients with endometriosis, and therefore may be involved in the pathophysiology of endometriosis[10-12].

Table 2. Correlations between levels of mRNAs encoding CLRs and immunoglobulin concentrations in the control group.

\begin{tabular}{|c|c|c|c|c|c|c|}
\hline \multirow{2}{*}{$\begin{array}{l}\text { Control } \\
\text { group }\end{array}$} & \multicolumn{2}{|l|}{$\mathrm{IgG}$} & \multicolumn{2}{|l|}{$\operatorname{Ig} A$} & \multicolumn{2}{|l|}{$\operatorname{IgM}$} \\
\hline & $\begin{array}{l}\text { Pearson's } \\
\text { Coefficients }\end{array}$ & $\begin{array}{l}\mathrm{P} \\
\text { value }\end{array}$ & $\begin{array}{l}\text { Pearson's } \\
\text { Coefficients }\end{array}$ & $\begin{array}{l}\mathrm{P} \\
\text { value }\end{array}$ & $\begin{array}{l}\text { Pearson's } \\
\text { Coefficients }\end{array}$ & $\begin{array}{l}\mathrm{P} \\
\text { value }\end{array}$ \\
\hline Dectin1 & -.040 & .802 & .043 & .787 & -.028 & .861 \\
\hline MR1 & -.171 & .280 & .076 & .630 & -.139 & .378 \\
\hline MR2 & -.013 & .939 & -.016 & .923 & -.062 & 3716 \\
\hline DCSIGN & .382 & .023 & .143 & .411 & .177 & .309 \\
\hline Syk & .206 & .208 & .276 & .089 & .010 & .953 \\
\hline Card 9 & .220 & .157 & -.114 & .466 & .264 & .087 \\
\hline Bcl 10 & -.074 & .648 & -.162 & .311 & -.180 & .260 \\
\hline Malt 1 & .253 & .097 & .093 & .548 & .201 & .191 \\
\hline Src & .315 & .054 & -.082 & .625 & .415 & .010 \\
\hline Dec 205 & -.040 & .805 & .133 & .406 & -.157 & .326 \\
\hline Galectin & .025 & .870 & .040 & .795 & -.009 & .951 \\
\hline Tim3 & -.014 & .931 & -.125 & .431 & -.064 & .689 \\
\hline Trem1 & .215 & .166 & .132 & .401 & .018 & .908 \\
\hline DAP12 & .380 & .012 & -.095 & .545 & .156 & .316 \\
\hline
\end{tabular}

Table 3. Correlations between levels of mRNAs encoding CLRs and immunoglobulin concentrations in the endometriosis group.

\begin{tabular}{lllllll}
\hline Endometriosis & IgG & \multicolumn{3}{l}{ IgA } & \multicolumn{2}{l}{ IgM } \\
& Pearson's & P & Pearson's & P & Pearson's & P \\
& Coefficients & value & Coefficients & value & Coefficients & value \\
\hline Dectin1 & 0.58 & .631 & .161 & .181 & .209 & .080 \\
MR1 & .136 & .260 & -.058 & .635 & .008 & .947 \\
MR2 & .065 & .607 & -.075 & .552 & -.011 & .930 \\
DCSIGN & .018 & .893 & -.032 & .816 & .011 & .935 \\
Syk & .001 & .994 & 0.69 & .573 & .250 & .038 \\
Card 9 & .108 & .374 & -.016 & .896 & -.049 & .685 \\
Bc1 10 & .208 & .081 & .263 & .026 & .016 & .893 \\
Malt 1 & .076 & .528 & .093 & .443 & -.054 & .655 \\
Src & .057 & .661 & -.150 & .247 & .005 & .972 \\
Dec 205 & .051 & .684 & .093 & .456 & .199 & .106 \\
Galectin & .168 & .162 & .149 & .214 & -.053 & .659 \\
Tim3 & .146 & .229 & .000 & .998 & -.103 & .394 \\
Trem1 & .114 & .348 & .171 & .157 & .242 & .043 \\
DAP12 & .076 & .530 & .073 & .550 & -.044 & .719 \\
\hline
\end{tabular}

Table 4. Correlations between levels of mRNAs encoding CLRs and immunoglobulin concentrations in the gynecologic cancer group.

\begin{tabular}{lllllll}
\hline Cancer & IgG & \multicolumn{3}{l}{ IgA } & \multicolumn{3}{l}{ IgM } \\
\hline & $\begin{array}{l}\text { Pearson's } \\
\text { Coefficients }\end{array}$ & P value & $\begin{array}{l}\text { Pearson's } \\
\text { Coefficients }\end{array}$ & P value & $\begin{array}{l}\text { Pearson's } \\
\text { Coefficients }\end{array}$ & P value \\
\hline Dectin1 & .191 & .408 & .228 & .319 & .058 & .802 \\
MR1 & .332 & .142 & .295 & .195 & .104 & .655 \\
MR2 & .034 & .886 & -.014 & .953 & .181 & .445 \\
DCSIGN & -.848 & .008 & -.636 & .090 & -.651 & .080 \\
Syk & .404 & .078 & .521 & .018 & .150 & .528 \\
Card 9 & .171 & .471 & .040 & .868 & -.040 & .866 \\
Bc1 10 & -.141 & .542 & -.239 & .297 & -.202 & .379 \\
Malt 1 & .267 & .255 & .353 & .127 & .061 & .799 \\
Src & -.079 & .756 & -.154 & .543 & -.012 & .964 \\
Dec 205 & .337 & .135 & .425 & .055 & .079 & .734 \\
Galectin & .421 & .057 & .285 & .211 & .373 & .096 \\
Tim3 & .290 & .215 & .273 & .244 & .043 & .858 \\
Trem1 & .283 & .214 & .194 & .400 & .242 & .291 \\
DAP12 & .266 & .245 & .177 & .442 & .044 & .849 \\
\hline
\end{tabular}

The aim of this study was to compare the expression of mRNAs encoding CLRs and their adaptor molecules associated with innate immune responses, as well as their patterns of expression, in patients with benign diseases, endometriosis, and malignant tumors. We found that mRNAs encoding 14 types of C-type lectin receptors and their adaptor molecules were expressed in all intraperitoneal fluid samples of the three groups. Relative to the other groups, Malt-1 mRNA was higher in the normal control group, DAP 12 mRNA was higher in the endometriosis group, and $\mathrm{Bcl}-10 \mathrm{mRNA}$ was higher in the gynecologic cancer group, indicating that type of disease affects the expression of mRNAs encoding different types of C-type lectin receptors and their adaptor molecules in the abdominal cavity. The endometriosis group differed from the gynecologic cancer group, in that the levels of MR1, MR2, Syk, Card 9, Malt 1, Dec 205, Tim 3, and DAP mRNAs were higher and the level of $\mathrm{Bcl} 10 \mathrm{mRNA}$ lower in the endometriosis group. The endometriosis group also differed from the normal control group, in that the levels of MR2 and Dec 205 mRNAs were higher and the level of galectin mRNA lower in the endometriosis group. These findings suggest that MR2, Dec 205, and Galectin mRNAs, which have the same expression patterns in endometriosis and cancer patients, but differ in the endometriosis and control groups, are associated with the progression and spread of endometriosis.

Endometriosis is an autoimmune disease, characterized by an increase in specific IgG autoantibody in peritoneal fluid and significant increase in $\operatorname{IgG}$ and $\operatorname{IgA}$ in endometrial glandular 
epithelial cells. Moreover, it has been suggested that patients with increased IgG should be treated for possible "precursor endometriosis" [13-15].This study found that $\operatorname{IgG}$, IgA, and IgM were secreted into the peritoneal fluid of patients in all three groups. The concentrations of secreted $\operatorname{IgA}$ and $\operatorname{IgG}$ were significantly lower in the gynecologic cancer than in the control group. However, the concentrations in the endometriosis group did not differ from those in each of the other groups.

This study also tested correlations between CLR mRNA levels and Ig secretion in the abdominal cavity. In the normal group, DC-SIGN and DAP 12 mRNA levels correlated with IgG concentration and Src mRNA level correlated with IgM concentration. In the endometriosis group, Bcl 10 mRNA correlated with IgA concentration and Syk and Trem 1 mRNA levels with IgM concentration. In the gynecologic cancer group, significant correlations were observed between DC-SIGN mRNA and IgG and between Syk mRNA and IgA. Expression of C-type lectin receptors, Ig secretion, and their mutual interactions constitute complex immune responses, making it difficult to understand the pathophysiology of endometriosis simply by assessing their expression, secretion and correlation.

This study had several limitations. First, we assessed effusion fluid, not tissue samples. Immune responses in the abdominal cavity may differ from immune responses in tissues and organs. Second, the present study assessed mRNA, not protein, levels. Therefore, we may have included samples in which mRNA is expressed but protein is not. Third, we did not correlate immunity with the severity of disease; and in patients with gynecologic cancer group, we did not correlate immunity with cell type, stage, or degree of differentiation.

\section{Conclusions}

We observed expression of mRNA of 14 types of C-type lectin receptors and their adaptor molecular mRNA in the effusion fluid of patients in the control, endometriosis, and gynecologic cancer groups. And Malt-1 mRNA in normal control group, DAP 12 mRNA in endometriosis group, and Bcl-10 mRNA in gynecologic group is higher than the other groups. Intraperitoneal IgG, $\operatorname{IgA}$, and IgM were secreted in the control group, endometriosis, and gynecologic cancer group. IgA and IgG concentrations in peritoneal fluid were significantly lower in the gynecologic cancer than in control group. CLRs and their adapter molecules mRNA and IgG, IgA, and IgM act cooperatively and are closely associated in the pathogenesis of endometriosis.

\section{Acknowledgement}

This work was supported by the National Research Foundation of Korea (NRF) grant funded by the Korea government (MEST) (No. 20120009380), (No. 2017R1D1A1B03030021), and Korea Gynecologic Cancer bank [KGCB]) of the Infrastructure Project for Basic Science of the Ministry of Education, Science, and Technology (MEST), Korea.

\section{Competing Interests}

The authors have declared that no competing interest exists.

\section{References}

1. Berker B, Seval M. Problems with the diagnosis of endometriosis. Womens Health (Lond). 2015 Aug;11(5):597-601

2. Vlahos NF, Kalampokas T, Fotiou S. Endometriosis and ovarian cancer: a review. GynecolEndocrinol. 2010 Mar;26(3):213-9.

3. Czyzyk A, Podfigurna A, Szeliga A, Meczekalski B. Update on endometriosis pathogenesis. Minerva Ginecol. 2017 Oct;69(5):447-46

4. Ruderman R, Pavone ME. Ovarian cancer in endometriosis: an update on the clinical and molecular aspects. Minerva Ginecol. 2017 Jun;69(3):286-294

5. Ozerkan K, Oral B, Uncu G. Mannose-binding lectin levels in endometriosis. FertilSteril. 2010 Jul;94(2):775-6

6. Kavoussi SK, Mueller MD, Lebovic DI. Expression of mannose-binding lectin in the peritoneal fluid of women with and without endometriosis. FertilSteril. 2006 May;85(5):1526-8.

7. Corzo C, BarrientosSantillan N, Westin SN, Ramirez PT. Updates on Conservative Management of Endometrial Cancer. J Minim Invasive Gynecol. 2017 Aug 3. pii: S1553-4650(17)30410-7

8. Heong V, Ngoi N, Tan DS. Update on immune checkpoint inhibitors in gynecological cancers. J GynecolOncol. 2017 Mar;28(2):e20. doi: 10.3802/jgo. 2017.28.e20. Epub 2016 Dec 14. Review

9. Menderes G, Hicks C, Black JD, Schwab CL, Santin AD. Immune checkpoint inhibitors in gynecologic cancers with lessons learned from non-gynecologiccancers. Expert OpinBiolTher. 2016 Aug;16(8):989-1004

10. Yeo SG, Won YS, Lee HY, Kim YI, Lee JW, Park DC. Increased expression of pattern recognition receptors and nitric oxide synthase in patients with endometriosis. Int J Med Sci. 2013 Jul 30;10(9):1199-208

11. Khan KN, Kitajima M, Fujishita A, Nakashima M, Masuzaki H. Toll-like receptor system and endometriosis. J ObstetGynaecol Res. 2013 Aug;39(8):1281-92

12. Yamada Y, Shigetomi H, Onogi A, Haruta S, Kawaguchi R, Yoshida S, et al. New insights into pattern recognition receptors and their ligands in gynecologic pathologies. Hum Immunol. 2011 Mar;72(3):213-8

13. Yeo SG, Won YS, Kim YI, Lee JW, Choi YJ, Park DC. Decreased Bcl-6 and increased Blimp-1 in the peritoneal cavity of patients with endometriosis. ClinExpObstet Gynecol. 2015;42(2):156-60

14. Mathur S, Garza DE, Smith LF. Endometrial autoantigens eliciting immunoglobulin $(\mathrm{Ig}) \mathrm{G}, \operatorname{IgA}$, and IgM responses in endometriosis. Fertilsteril 54: 56-63, 1990.

15. Saifuddin A, Buckley $\mathrm{CH}$, Fox $\mathrm{H}$. Immunoglobulin content of the endometrium in women with endometriosis. Int J Gynecol Pathol 2: 255-63, 1983. 